\title{
DERECHO Y DEMOCRACIA
}

ué es lo que queremos decir exactamente cuando usamos el término
«democracia»? Creo que la mayoría de nosotros nos referimos a lo mismo:
una sociedad libre en la cual todos los ciudadanos gozan de libertad de
expresión y cuyo gobierno se elige de acuerdo con el voto emitido por la
mayoría en unas elecciones libres. En otras palabras, una democracia es una sociedad donde el pueblo gobierna.

No creo que esta definición de democracia vaya a causar gran polémica, dado que es la generalmente aceptada en el mundo libre. Sin embargo, si vamos un poco más lejos en el análisis del término, advertimos que: las cuestiones que englobamos bajo el rótulo de la democracia, cómo pensamos que debería estar organizada una buena democracia y cómo nos gustaría describir la relación entre el gobierno y las demás autoridades por una parte y los ciudadanos por otra, y la relación entre gobierno/ autoridades y Derecho, no son sencillas de responder y suscitan algunos problemas.

En primer lugar me parece que puede ser buena idea mencionar algunas exigencias o características que son necesarias en una sociedad democrática. Sin ir más lejos, ya podemos advertir que hay diferentes definiciones. Hay, pues, diferentes concepciones de democracia que quisiera tratar: ¿Deberá un gobierno, una vez elegido por la mayoría de los votantes, ser libre de hacer lo que quiera o es necesario limitar el poder de las autoridades de una sociedad de una manera u otra (v. gr. mediante la imposición/inclusión en la Constitución de normas relativas a la inviolabilidad de los derechos humanos)? La tercera cuestión que me gustaría apuntar se refiere al modo generalizado en que la palabra democracia se usa en el debate político y la tendencia a extender el área donde la democracia sería considerada lo ideal desde la vida política por ejemplo a la vida económica («democracia eco- 
nómica»), los colegios («democracia educativa») o incluso las familias («democracia familiar»).

En este breve examen me referiré principalmente a la discusión en Suecia y otros países nórdicos. Puede ocurrir que los temas que se tratan aquí presenten algunas características propias del debate en el norte de Europa, y en Suecia particularmente; con todo, pienso que estas cuestiones merecen ser tratadas en todas las democracias.

\section{Los elementos básicos de una democracia}

Estoy convencido de que casi todos los demócratas que quieren describir qué es una democracia y cuáles son las características de un Estado democrático, lo harían básicamente de la misma manera; como una sociedad gobernada por el pueblo, donde el poder estatal pertenece y deriva del pueblo. No obstante, si la tarea consiste en definir el término democracia de forma más específica, pueden ofrecerse varias descripciones diferentes, según cuáles sean nuestras exigencias frente a la democracia.

Así, el profesor finés Lars Erik Taxell distingue tres elementos básicos necesarios para una democracia, a saber: la participación del pueblo en el proceso político, que tiene lugar cuando el pueblo elige a los representantes que ejercerán el poder en su nombre; esta participación sólo puede ser real mediante un derecho al voto igual y general. Una libertad de opinión en virtud de la cual los ciudadanos puedan expresar su parecer en público. Y por último, pero no por eso menos importante, el hecho de que en cuestiones de interés social donde las opiniones difieran, las decisiones se tomen según lo que exprese la mayoría, con las limitaciones que exige la necesidad de proteger a determinados grupos e individuos. Esta última observación afecta a un problema fundamental en todas las democracias que trataré después.

El conocido danés Alf Ross caracterizó la democracia como un método político y una forma de organización del Estado. También advirtió que el término democracia, tomado en sí mismo, no decía nada sobre el contenido real sobre el tipo de política a ejercer mediante tal método. Sin embargo, Ross afirma que aunque esto supone que la democracia en sí misma no basta para garantizar a cualquier individuo alguna libertad particular o derecho humano, hay un número de libertades vinculadas muy de cerca a la democracia, toda vez que sin ellas el principio del gobierno de la mayoría perdería su sentido. Sobre todo se refiere 
a la libertad de expresión y a la libertad de asociación. Me parece que es aquí donde Ross incide en la cuestión clave a discutir: ¿puede funcionar una democracia sin derechos humanos garantizados jurídicamente de alguna manera, ya sea en la Constitución, mediante convenciones internacionales...?

Aleksander Peczenik considera que el concepto moderno de democracia está ligado a determinados juicios de valor. Al denominar democrática a un determinado tipo de sociedad o a un determinado país, expresamos nuestra apreciación. Una definición de democracia libre de valoración, que simplemente equipare la democracia con las decisiones de la mayoría, según Peczenik, no sería acorde con el lenguaje cotidiano. Incluso si "gobierno de la mayoría» es la idea central de la democracia, Peczenik considera que es posible probar si una sociedad es democrática o no, mediante el examen del lenguaje político. Esto puede hacerse examinando si ciertos hechos, determinadas características que son necesarias para la existencia de una democracia, se dan de hecho en un Estado. Tales características son:

1. Que el poder se ejerza por personas que verdaderamente representen los intereses del pueblo.

2. Decisiones mayoritarias mediante elecciones libres.

3. Derechos humanos. Peczenik no sólo incluye entre los derechos necesarios algunos tales como la libertad de expresión, sino que además menciona la mayoría de los derechos humanos enumerados por ejemplo en la Convención Europea de Derechos Humanos.

4. «Imperio de la ley» («Rule of Law»), los derechos [jurídicos] del individuo, lo que supone de forma más específica, que las leves deben ser previsibles o susceptibles de conocimiento previo en lo que se refiere a su modo de operar, y que tienen que ser aceptables desde un punto de vista ético.

5. División de poderes. Ni siquiera el parlamento deberá detentar todo el poder. Por ejemplo, la independencia de los tribunales es algo característico de la democracia.

6. Que las personas que ejercen el poder sean responsables de sus acciones.

7. La participación del ciudadano en la vida política.

Esta enumeración muestra que el término democracia también puede describirse de forma más clara y concreta. No obstante, la cuestión relativa a cómo describir los elementos básicos de una democracia no es precisamente la más difícil cuando examinamos el debate en torno a la democracia, aunque como hemos visto haya variedad de opiniones. La forma en que una democracia debería ponerse en práctica ha sido un asunto de 
discusión permanente desde su nacimiento. Por ello me gustaría tratar ahora este tema.

2. ¿Cómo debería ponerse en práctica una democracia o puede haber democracia sin derechos individuales?

Probablemente ninguna cuestión ha sido tan discutida en la historia de la filosofía política como los problemas relacionados con cómo es o debería ser ejercitado el poder en un Estado democrático. Debo referirme aquí a la discusión entre Burke y Thomas Paine sobre las consecuencias de la revolución francesa y la advertencia de Alexis de Tocqueville tras su visita a América sobre los riesgos propios de la democracia y el gobierno de la mayoría.

El noruego Rune Slagstad trató de hacer un análisis histórico de este problema identificando tres influencias que dominaban las teorías del Derecho y del Estado, susceptibles de múltiples combinaciones: la herencia de Maquiavelo, de Aristóteles y del liberalismo. Según Slagstad, la influencia de Aristóteles acentúa la dimensión ética de la vida política. Esta es la doctrina que trata de cómo deberían comportarse los ciudadanos para vivir una vida buena y de cuál sería la mejor forma en que debería organizarse la sociedad para permitírselo. El liberalismo destaca el constitucionalismo y la posibilidad de limitar y regular el poder del Estado, «limitarlo» mediante el Derecho. La cuestión clave es: ¿Cómo asegurar que el Estado estará limitado por sus propias leyes? El propósito del liberalismo es, en este sentido, evitar la identificación entre el poder y la justicia. O dicho con las palabras de Slagstad «¿En qué sentido puede -y quiere- el Estado estar limitado por sus propias leyes? Cuando las leyes, por así decirlo, son el lenguaje propio del Estado y el Estado democrático gobernado por el Derecho tiene el poder de crear cualquier ley, el fundamento para que este Estado sea gobernado por la ley puede cambiar rápidamente». La herencia de Maquiavelo insiste en que la política no tiene nada que ver con la ética. Lo único que importa ahora es como gobernar y controlar a los ciudadanos de una forma que asegure la supervivencia del Estado. La política se transforma en una cuestión de poder estratégica que no tiene nada que ver con la moral o la justicia (por supuesto esto no significa que a Maquiavelo no le interesara en absoluto la moral o la justicia, sino que pretendía separar la política de los valores éticos). Esta herencia es especialmente importante en los países nórdicos, debido al gran impacto que allí 
ha tenido el realismo jurídico en la filosofía del Derecho durante el siglo XX. Slagstad nombra a Maquiavelo padre espiritual e ideológico de este realismo y hace hincapié en la gran importancia que han tenido en Escandinavia «los realistas jurídicos escandinavos».

Si nos fijamos en la situación actual en Suecia -que es el único país que conozco lo bastante como para estar seguro en este punto- creo que es justo admitir que el realismo tiene una posición privilegiada, arraigada en el debate científico y como luz orientadora de políticos y autoridades, que guía su visión de sus propios poderes. Como apunta Slagstad, es característico de este realismo cuando actúa en la vida práctica que el Derecho se vaya dirigiendo cada vez más hacia ciertos objetivos. Las leyes pasan a ser instrumento de cambios sociales y políticos más que la expresión de ciertos principios o ideales de justicia. El propósito del Derecho se convierte en la realización o cumplimiento de las ambiciones políticas de los gobernantes.

Hay diversas explicaciones sobre el fuerte arraigo que el realismo tiene en Suecia (y, en consecuencia, de la relativa debilidad del liberalismo, los derechos humanos, el constitucionalismo y la división de poderes). Entre las más frecuentes se encuentran: el desarrollo pacífico de la sociedad sueca, donde los ciudadanos nunca han tenido que luchar por sus derechos civiles; el gran impacto que han tenido filósofos realistas como Hägerström y Olivecrona, durante más de medio siglo, en la forma de pensar de los abogados suecos y en su concepción del Derecho y la justicia; y la larga hegemonía del mismo partido político.

Sin embargo, no pretendo discutir aquí con detalle este amplio tema. Antes bien, me gustaría centrarme en dos aspectos de la discusión que se mantiene hoy en Suecia, sobre todo en la manera un tanto confusa en que se están utilizando los derechos humanos, los derechos civiles y demás concepciones, y la forma en que debe entenderse el «imperio de la ley» («Rule of Law»), los derechos [jurídicos] del individuo.

Respecto a la primera cuestión, resulta paradójico que los derechos civiles hayan sido históricamente bastante bien respetados en Suecia a pesar de que varios representantes de los diferentes gobiernos hayan declarado abiertamente que los derechos humanos es un concepto inútil carente de sentido. Es justo reconocer que en general los jueces suecos y demás juristas, no se sienten a gusto cuando se enfrentan a problemas relacionados con derechos humanos. Surge, pues, el recuerdo de la herencia de Hägerström y otros realistas, que enseñan que no existen cosas tales como los «derechos», pues los derechos no pueden ex- 
plicarse de forma lógica al no ser más que valoraciones de cosas que la sociedad o la gente en general contempla como «buenas».

Podemos poner varios ejemplos de la débil posición que tienen en la sociedad sueca los derechos humanos o los también llamados derechos civiles, no en la vida diaria sino como una idea, como una concepción. Me gustaría tratar aquí el uso equivocado de la expresión derechos civiles tal y como aparece entre la propuesta socialdemócrata de un nuevo programa para el partido. Como he dicho, podrían ponerse muchos más ejemplos. No obstante, éste es un asunto que merece la pena examinar.

Mi principal argumento para tratar esta cuestión es que derechos humanos y derechos civiles significan casi lo mismo y deben entenderse en el mismo sentido. Si tuviéramos que diferenciarlos, diría que un derecho humano puede concebirse como algo que cualquier individuo en el mundo puede exigir, mientras que un derecho civil pertenece a cualquier ciudadano de un Estado concreto. Lo que ambos conceptos tienen en común es sobre todo que están relacionados con los individuos y que en una sociedad gobernada por el Derecho (en un Estado de Derecho), donde están reconocidos, pueden ser alegados o exigidos por cualquier individuo frente al Estado. No obstante, en la propuesta de nuevo programa para el partido, los socialdemócratas están usando el término derechos civiles de una forma distinta.

Así, en lugar de hablar de derechos civiles, relacionados con los individuos en la sociedad sueca, los ciudadanos suecos, los socialdemócratas hablan de un «derecho ciudadano» del que se dice que es superior a derechos humanos tales como el derecho de propiedad. (El programa no dice si también es superior a v. gr. la libertad de expresión.)

¿Cuál es, pues, el significado, el contenido de este «derecho ciudadano»? La verdad es que la expresión no está bien definida en esta propuesta socialdemócrata. Cuando se utilizó por vez primera en el debate de 1986 para justificar un impuesto especial sobre pensiones privadas que fue muy discutido desde puntos de vista constitucionales, el primer ministro lo usó de forma que quedaba claro que concebía el «derecho ciudadano» -que se manifiesta en las decisiones que toma la mayoría en el parlamento- como superior por lo menos a algunas de las normas sobre derechos humanos de la Constitución sueca. También lo describió como algo más amplio que el derecho al voto y afirmó que resulta decisivo para las posibilidades del individuo ejercer una influencia en la sociedad. Pero esto va más allá de la concepción tradicional de los derechos civiles.

En esta propuesta de programa para el partido se definía 
como derechos civiles el acceso de los ciudadanos a instancias tales como el cuidado de los niños, educación, cultura y hospitales, lo cual resulta bastante raro. Por ejemplo, si miramos las dos convenciones de la ONU de 1966, en ellas se advierte una distinción entre los derechos civiles y los derechos «económicos, sociales y culturales». Pero los socialdemócratas suecos consideran que es más fácil reconocer este tipo de derechos sociales, tal como los llamamos nosotros, desde que por así decirlo se dan a los individuos por el Estado y no como derechos que pertenecen a los individuos como tales. El partido encuentra mucho más difícil admitir la forma tradicional de los derechos civiles o, para ser más específico, los aceptan pero no quieren que constituyan de alguna manera una limitación al gobierno de la mayoría.

El programa también dice que el sector público de la economía ha tenido gran importancia al movilizar grandes grupos de ciudadanos en torno a la idea de un «derecho ciudadano» básico, que evidentemente muestra que «derecho ciudadano» significa algo más que los derechos civiles en sentido tradicional. Por tanto, creo que es honesto reconocer que para los socialdemócratas suecos, la democracia significa que la mayoría gobierna y que el «derecho ciudadano» -que en ningún modo equivale a los derechos civiles en el sentido tradicional de la expresión- se pone en práctica por la mayoría en el parlamento, que no estará muy limitada por normas sobre derechos humanos inviolables.

Es interesante comparar esta concepción de la democracia con la de Taxell, quien afirmó que puede elaborarse un modelo teórico de democracia en dos sentidos. En el primero, lo que él llama la concepción formal de democracia, entiende la democracia como un método o un sistema para la toma de decisiones en los asuntos de la sociedad. La democracia se transforma en una técnica para adoptar decisiones y no entra en el contenido de tales decisiones. En el segundo, llamado la concepción material de democracia, no excluye el primero sino que lo amplía. Esta concepción atiende al contenido de las decisiones tomadas en un orden democrático. Se especifican algunos valores que siempre deberán respetarse, de manera que la democracia adquiere un contenido material.

Como dice Taxell, ambas formas de vislumbrar la democracia no difieren mucho entre sí. Es posible construir un modelo teórico de democracia aun sin contar con sus elementos materiales -los valores de la democracia, como los llama Taxell-pero, como él dice, si la tarea consiste en proteger la democracia en una sociedad no podemos pararnos justo en el «proceso obligado de toma de decisiones». Si las decisiones no cuentan con unos 
principios básicos relativos a su contenido, la democracia se parecerá a un sistema vacío que podrá ser maltratado por movimientos con aspiraciones totalitarias.

La otra cuestión que me gustaría analizar es cómo debe entenderse la idea del «imperio de la ley» («Rule of Law»). Aquí debo volver al núcleo de la discusión en lo referente a la situación sueca. Estoy seguro de que la mayoría de nosotros contempla este asunto, tal como vemos los derechos humanos, como algo ligado al individuo, un problema de los derechos [jurídicos] del individuo y de su protección jurídica, especialmente frente al Estado. Por tanto, la pregunta debe ser: ¿Qué exigencias debemos incluir en las nuevas leyes para que garanticen, hasta un punto razonable, aquellos derechos subjetivos del individuo?

En un informe gubernamental presentado hace unos cinco años por el departamento de justicia sueco, referente a delitos económicos, el anterior ministro de justicia sueco realizaba una distinción entre imperio de la ley formal y material («Rechtssicherheit»), donde el primero entrañaba la vigencia del principio de igualdad ante la ley y el principio de legalidad, v. gr. que los ciudadanos pudieran saber de antemano cómo funciona la ley en la realidad; mientras que el material suponía que los ciudadanos podían sentirse protegidos en su integridad, que no se cometerían muchos delitos y que los delitos cometidos serían castigados. Una comisión parlamentaria que comentó este informe no respaldó la distinción, pero recomendó como definición adecuada de imperio de la ley la que el ministro de justicia había empleado para describir el imperio de la ley formal. Después de esto, el departamento de justicia se ha servido de esta última definición en discusiones relativas a otras leyes, por lo que ésta parece ser la que guía por ahora la actividad de las autoridades legislativas en Suecia.

Peczenik ha cuestionado esta definición y considera que el imperio de la ley significa que las leyes deben ser a la vez previsibles y éticamente aceptables. Lo ha ilustrado con el ejemplo siguiente: los judíos en la Alemania nazi podían prever con facilidad que iban a ser perseguidos, pero nadie podía llamar a esto un buen imperio de la ley. Personalmente, sólo añadiría que la definición de imperio de la ley arriba citada es una definición parcial, que al no considerar el punto de vista ético, hasta el punto que democracia simplemente significa lo que la mayoría ordena -sin ninguna consideración hacia los derechos humanos-, proporciona al partido en el poder grandes posibilidades de elaborar cualquier tipo de leyes, incluso aquellas leyes totalmente inaceptables desde una perspectiva ética. Y entonces un 
Estado democrático de Derecho puede convertirse rápidamente en otra cosa muy distinta.

\section{El amplio uso de la palabra democracia}

Últimamente el debate en torno a la democracia ha estado caracterizado a menudo por un uso amplio de este término. Me refiero a expresiones tales como «democracia económica», «democracia educativa», «democracia en el trabajo» y demás. Para poner algunos ejemplos recientes, citaré un fragmento de la nueva propuesta socialdemócrata de programa para el partido: «La democracia política es básica. Pero para alcanzar su pleno efecto, la democracia debe abarcar el campo de la producción.» «Si la sociedad democrática ha de culminarse por entero, el campo productivo no puede ser excluido de las normas democráticas.» «Los socialdemócratas quieren renovar las condiciones de trabajo extendiendo la democracia a la vida laboral.»

¿Cómo ha de relacionarse esta democracia ampliada con la democracia política? Personalmente, considero que sólo es útil utilizar la voz democracia en el tradicional sentido político. El término democracia, tomado en sí mismo, supone un tipo de organización de la sociedad y una forma pública de tomar decisiones, donde el pueblo gobierna, y nada más. (En este punto coincido con Ross. Otra cosa son las condiciones en que la democracia puede existir y prosperar mejor. En mi opinión, cuando tratamos esta cuestión procede recordar lo que Taxell llama los valores de la democracia). Cuando se interpreta jurídicamente, la democracia está ligada al campo del Derecho constitucional, y no al del Derecho del trabajo, por ejemplo. La concepción amplia de la democracia ignora, como afirma Taxell, que la democracia deriva del pueblo -v. gr. todos los ciudadanos de una sociedad- y que descansa en la condición de que todas las situaciones donde el pueblo intervenga en la toma de decisiones -en casa, en el trabajo o donde sea- puedan describirse como si la democracia estuviera funcionando.

Ross también se muestra escéptico frente a este uso amplio del término democracia. En lo relativo a la expresión «democracia económica», advierte que a menudo se usa para caracterizar un orden económico que puede ser más igualitario y justo que el presente, y considera que esta utilización de la palabra democracia resulta confusa pues no cabe analogía entre la «democracia económica» y la tradicional democracia política. La democracia política implica una forma de gobierno y las ideas de libertad que de ese modo pueden desarrollarse. El mero hecho de distri- 
buir el crecimiento y la idea de igualdad económica están más allá de la concepción de democracia.

Ross también destaca el riesgo que conlleva este uso ambiguo del término democracia para designar fenómenos económicos -o culturales, «democracia cultural»- que no son análogos a la democracia política ni en su estructura ni en sus ideas. Al final puede conducir a una situación absurda en que la expresión democracia pueda utilizarse para designar sociedades que no pueden considerarse democráticas en el sentido tradicional sino extremadamente autoritarias o incluso dictatoriales (v. gr. «La República Democrática Alemana», el ejemplo es mío). En todo caso, esto muestra el cuidado que hay que tener al utilizar la palabra democracia.

\section{Algunos comentarios finales}

Los temas que se han tratado en este breve estudio son sólo parte de los múltiples argumentos desde los que puede debatirse la democracia. Y, como hemos visto, incluso los demócratas convencidos tienen diferentes concepciones de la democracia. Esto hace que la democracia sea especialmente interesante como concepción, como idea; es indiscutible, desde que todo el mundo la quiere, y al mismo tiempo difícil de analizar y susceptible de ser entendida de diversas maneras.

Aquí he hablado mucho -y de forma bastante crítica- sobre la situación en Suecia. No es porque me cause especial placer criticar las circunstancias de mi propio país. Lo que trato de decir -y así lo ilustran los ejemplos tomados de Suecia, el único país que conozco lo bastante como para tener una opinión clara- es que incluso democracias sólidas pueden peligrar si los derechos humanos y el «imperio de la ley» no se respetan y se observan con cuidado, tanto en el plano teórico como en la vida real.

Sin embargo, lo que parece cierto es que continuará el debate sobre las condiciones de la democracia. Su desarrollo reciente y satisfactorio en Europa Central y Oriental, añadirá sin duda inspiración y muchos argumentos a la discusión. Por tanto, el futuro de la democracia no parece demasiado sombrío.

(Trad. de Mercedes Carreras) 